\title{
Research on the gravity planning model of prefecture city rail transit network
}

\author{
Tianwen Liang ${ }^{1}$, Huan Liu $^{2 *}$, Yong Tan ${ }^{3}$ \\ 1,2 Research Institute of Highway Ministry of Transport, Beijing, 100086, China \\ ${ }^{3}$ Renxin Management Office of Renbo expressway management center of south Guangdong Communications, 512000, China
}

\begin{abstract}
The rational layout of prefecture city rail transit network is of great significance to the coordinated development of urban and rural areas. This paper analyses five related factors that affect the layout of rail transit and grey relation analysis is used to analyse the correlation degree and weight of five related factors. Based on this, an improved gravity model describing the attraction between towns is built. The improved gravity model is used as the road weight, and the urban rail transit network layout is obtained by graph theory Kruskal algorithm. Finally, taking the urban rail transit network in Handan as an example, the rationality and feasibility of the model and layout method are checked.
\end{abstract}

\section{Introduction}

The overall development of urban and rural areas is an important measure to build a well-off society in an allround way in the new era. The complementary resources, advantages and common development strategies between urban and rural areas make the contact and communication between urban and rural areas closer. In order to promote the coordinated economic development between cities, the construction of convenient rail transit system is particularly important. By 2017, China has opened 185 intercity rail transit lines, and the main framework of intercity rail transit has begun to take shape. Intercity rail transit can meet the needs of medium and long-distance, high-density passenger travel between large cities, but it cannot meet the convenient requirements of small and medium-sized cities, medium and short-distance passenger travel. Therefore, it is a trend to encrypt the backbone network of rail transit and form the internal rail transit network of prefecture level cities. Therefore, it is necessary to study the layout method of urban rail transit network.

The research of domestic and foreign scholars on the layout of rail transit network mainly focuses on the planning of intercity rail transit network of urban agglomerations: Yuting Tu and others analysed the layout of intercity rail transit network by combining the node importance theory in highway planning and the traffic line interference theory in traffic location theory, and carried out the traffic network layout layer by layer using the optimal tree theory[1]. Jouwang Sun et al. Put forward some qualitative and quantitative analysis methods for the related problems in urban rail transit network planning, such as network scale, the relationship between planning and urban development, and the correlation between planning and land use [2]. Liu Xuan et al. built a social and economic network in the town area by improving the gravity model [3]. Zhiming Zhao et al. analysed the importance and economic gravity index of intercity rail transit nodes by using AHP, and put forward the dual optimization model of intercity rail main framework layout [4]. Based on the theory of traffic location, lege hu et al. established a two-level planning model of highway network layout based on genetic algorithm, and put forward a new method of urban agglomeration highway network planning and layout which integrates the node importance method and traffic location line method [5]. $\mathrm{Lu}$ Tao et al put forward four different forms of intercity rail transit layout, namely pendulum type, radial type, network type and bead type, according to the development status of urban agglomerations in China and the development mode of regional spatial structure, and expounded their different characteristics [6]. At present, most of the analysis methods of rail transit network planning are qualitative analysis, considering urban spatial layout, land use, passenger flow distribution, line network structure, social economy, etc. quantitative analysis is mainly reflected in passenger flow prediction and node importance analysis.

On the research of rail transit network layout using graph theory, Li Xiaoli et al. [7] studied the theory of minimum investment in the fast trunk line of Central Plains urban agglomeration by using the algorithm of minimum spanning tree. In this algorithm, only the distance between two places is considered, and there is a certain gap between the conclusion and the reality. Church et al. [8] divided the cells in the study area and scored them, accumulated the cell scores to get the cell weight value, and selected the line with the minimum weight by the shortest path method. This paper does not consider the impact factors, especially the travel needs of residents.

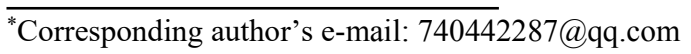


Tan Jianmei et al [9] constructed a multi-level optimization model of intercity rail transit network, and divided the intercity rail network into backbone network and preliminary line network. The optimization model of backbone network is the minimum spanning tree model with the reciprocal of economic connection strength as the weight. At present, scholars at home and abroad, based on the minimum spanning tree in the graph theory, have not considered the selection factors of the road weight in the layout planning of rail transit network, most of which are one or two, and have not considered the related factors such as political economy, tourism, population flow among cities and towns comprehensively.

The layout of urban rail transit network is not only affected by passenger flow, economy and other factors, but also comprehensively considered the political, industrial, cultural, tourism and other factors of each county. Therefore, in view of the characteristics of many influencing factors of urban rail transit network layout, this paper analyses the relevant influencing factors, and uses the gray correlation analysis method to calculate the index weight of the relevant influencing factors. Through the establishment of an improved gravity model to describe the mutual attraction between urban nodes, determine the weight of the road between urban nodes, use Kruskal algorithm to solve the minimum spanning tree, and provide a quantitative analysis method for the determination of urban rail transit network.

\section{Determination of influencing factors and correlation degree}

\subsection{Determination of relevant influencing factors}

The service radius and function of prefecture city rail transit is between urban rail transit and national railway trunk line, which mainly undertakes the passenger flow between cities and towns in short and medium distance. Therefore, core cities, sub core cities, important counties, tourist attractions and industrial parks are usually selected as nodes, and the function, status and role of each urban node in regional development are also considered [9-10].

The layout of prefecture city rail transit network depends on the function and nature of nodes. There are many factors that affect the function and nature of nodes, such as urban spatial layout, industrial layout, urban system structure, population scale, economic development status[11]. Therefore, this paper selects five factors that can be quantitatively analysed, including resident population, per capita disposable income (town), industrial added value, passenger volume and freight volume, as the basic indicators to determine the nature of urban nodes, that is, urban rail transit network layout. Therefore, this paper selects five basic indicators that can determine the nature of urban nodes and the layout of urban rail transit network, including resident population, per capita disposable income (urban), industrial added value, passenger volume and freight volume. The influence degree of the changes of five influencing factors on the properties of urban nodes can be determined by the grey correlation degree analysis method, and the weights of different influencing factors can be obtained by ranking according to the magnitude of the correlation degree.

\subsection{Calculation of index weight by grey correlation analysis}

Grey correlation analysis method is to find the numerical relationship among subsystems (or factors) in the system through certain methods [12]. As a typical grey system, the influencing factors of urban rail transit network layout are known, but their information is incomplete. In this paper, we choose the quantifiable influencing factors: resident population, industrial added value, passenger volume, freight volume, per capita disposable income (town) as the analysis sequence, urban quality as the reference sequence, based on the grey correlation analysis theory, to explore the correlation between the five indicators and the degree of impact on urban nodes. The calculation steps of weight coefficient are as follows [13]:

1) In order to eliminate the incommensurability caused by different dimensions, the initial value is used to unify the dimensions of each factor sequence:

$$
Y_{i j}^{\prime}=Y_{i j} / Y_{0 j}, \quad(\mathrm{i}=0,1,2 \ldots, \mathrm{n} ; \mathrm{j}=1,2, \ldots, \mathrm{m})
$$

2) Calculate the relationship coefficient between the reference sequence and the analysis sequence:

$$
r_{i j}=\frac{\min _{n} \min _{m}\left|Y_{0 j}^{\prime}-Y_{i j}^{\prime}\right|+\rho \max _{n} \max _{m}\left|Y_{0 j}^{\prime}-Y_{i j}^{\prime}\right|}{\left|Y_{0 j}^{\prime}-Y_{i j}^{\prime}\right|+\rho \max _{n} \max _{m}\left|Y_{0 j}^{\prime}-Y_{i j}^{\prime}\right|}
$$

Where: $r_{i j}$ is the grey correlation degree of analysis sequence $Y_{i j}^{\prime} \quad(\mathrm{i}=1,2, \ldots, \mathrm{n} ; \mathrm{j}=1,2, \ldots, \mathrm{m})$ with respect to reference sequence $Y_{0 j}^{\prime}(\mathrm{j}=1,2, \ldots, \mathrm{m}) ; \rho \in(0,1)$ is the resolution coefficient, usually takes 0.5 .

3) The correlation degree of the index is calculated by the correlation coefficient. Because $\left(r_{1 j}, r_{2 j}, \ldots, r_{n j}\right)$ reflects the correlation degree between the jth index value and the reference value of the $i(i=1,2, \ldots, n)$ analysis sequence, that is to say, it reflects the proportion of the jth index in the whole index space:

$$
w_{j}=\frac{1}{n} \sum_{i=1}^{n} r_{i j}, \quad(\mathrm{j}=1,2, \ldots, \mathrm{m})
$$

\section{Research on layout method based on improved gravity model}

Graph theory is a graph composed of some given points and lines connecting two points. This graph is usually used to describe the specific relationship between certain things. In traffic, the connection strength between two points, i.e. the road weight, is usually expressed by the linear weighted value of the distance between two points, comprehensive transportation cost and other related factors. Prefecture city rail transit network is a complex network diagram composed of point set and line set, which is different from the simple two points in transportation. The selection of urban rail transit network nodes generally considers political functions, economic positioning, transportation location and spatial layout. The measurement standard of the right of way between nodes is not only considering the distance, cost and other factors, but also closely related to the regional political, economic and traffic conditions. Therefore, in this paper, the 
improved gravity model is constructed to comprehensively influence the relevant factors of the mutual attraction between cities and towns, depict the communication activities between cities and towns, and take the interaction between cities and towns calculated by the model as the quantitative value of the right of way between the two places in the graph theory Kruskal algorithm.

\subsection{Gravity model of urban network research category}

There is a close relationship between the gravity model and the coefficient of universal gravitation. The intensity of social and economic ties between cities is directly proportional to the city quality and inversely proportional to the distance between cities [14-16]. The model expression is:

$$
F_{i j}=K \frac{P_{i} P_{j}}{D_{i j}^{r}}
$$

In the formula, $F_{i j}$ is the spatial interaction between cities and towns; $\mathrm{K}$ is the gravity coefficient, $\mathrm{r}$ is the friction coefficient, generally $\mathrm{k}=1, \mathrm{r}=2 ; P_{i} 、 P_{j}$ is the urban quality of the departure and destination respectively. It is commonly used in urban scale research to express urban GDP and non-agricultural population[17]; $D_{i j}$ is the European distance between cities.

\subsection{Construction of improved gravity model}

It is far from enough to select only urban GDP and nonagricultural population as the influencing factors of the interaction between cities and towns, especially in the area of prefecture level cities, the economic development level and population mobility of each county are different from those of big cities. Therefore, it is necessary to build an improved gravity model to make it more suitable for describing the interaction between counties, cities and districts in prefecture level cities. This paper describes the nature of urban nodes by selecting five basic indicators: permanent resident population, per capita disposable income (town), industrial added value, passenger volume and freight volume, and constructs an improved gravity model. The model expression is:

$W_{i j}=\frac{\alpha\left(\frac{P}{p_{i}+p_{j}}\right)+\beta\left(\frac{E}{e_{i}+e_{j}}\right)+\gamma\left(\frac{V}{v_{i}+v_{j}}\right)+\mu\left(\frac{C}{c_{i}+c_{j}}\right)+\delta\left(\frac{F}{f_{i}+f_{j}}\right)}{\frac{1}{d_{i j}}}$

Where, $\mathrm{i}$ and $\mathrm{j}$ represent the two connected counties and cities respectively; $W_{i j}$ is the road weight of $\mathrm{i}$ and $\mathrm{j} ; \mathrm{P}$ is the total resident population of the region (all counties and cities) (10000 people); $\mathrm{E}$ is the total disposable income per capita of the region (all counties and cities) (yuan); $\mathrm{V}$ is the total industrial added value of the region (all counties and cities) (100 million yuan); $\mathrm{C}$ is the total passenger traffic of the region (all counties and cities) (10000 people); $\mathrm{F}$ is the total freight traffic of the region (all counties and cities) (10000 tons); $p_{i} 、 p_{j}$ refers to the number of permanent residents in counties $i$ and $j(10000$ people); $e_{i}, e_{j}$ represents the per capita disposable income of $\mathrm{i}$ County and $\mathrm{j}$ county respectively (yuan); $v_{i}$ 、 $v_{j}$ represents the industrial added value of $\mathrm{i}$ County and $\mathrm{j}$ county respectively (100 million yuan); $c_{i}, c_{j}$ represents the passenger traffic volume of $\mathrm{i}$ County and $\mathrm{j}$ county respectively (10000 people); $f_{i}, f_{j}$ represents the freight volume of $\mathrm{i}$ County and $\mathrm{j}$ county respectively (10000 tons)

$\alpha, \beta, \gamma, \mu, \delta$ is the weight of five indicators: resident population, per capita disposable income, industrial added value, passenger volume and freight volume; $d_{i j}$ is the distance between $\mathrm{i}$ and $\mathrm{j}$, which can be searched and demarcated according to expressway, National Road, provincial road and county road.

\subsection{Kruskal algorithm of graph theory and its solution}

In a broad sense, urban traffic network is a network connected weighted graph, so it can be solved by Kruskal algorithm in graph theory. Firstly, the road network map of city planning is abstracted, and the roads at and above the county level connecting each node are searched in turn. If the two nodes can be connected by the roads at and above the county level, then the two nodes are connected by a virtual edge; If there is no such road between two nodes, there is no edge connection. The reason why the township road is not selected here is that the grade of the township road is low, and the connection of the two urban nodes through the township road indicates that the strength of the connection between the nodes is very weak, which may not be considered. Secondly, the weight between two nodes is calculated by improving the gravity model. Finally, Kruskal algorithm in graph theory is used to solve the minimum spanning tree of the undirected connected weighted graph, which is used as the layout of urban rail transit network. Let $G=(n, m)$ be an undirected connected nonnegative weighted graph. Where $\mathrm{G}$ is the graph; $\mathrm{n}$ is the number of vertices; $\mathrm{m}$ is the number of edges.

The Kruskal algorithm for finding the minimum spanning tree in $\mathrm{G}$ is given below. The main steps are as follows [18]:

1) Select an edge $e_{i}$ so that $W_{i j}$ is as small as possible.

If side $e_{1}, e_{2}, e_{3} \ldots \ldots e_{i}$ has been selected, then select $e_{i+1}$ 。 $\Phi \mathrm{G}\left\{e_{1}, e_{2}, e_{3} \ldots \ldots e_{i}, e_{i+1}\right\}$ no loop from $\mathrm{E}$ $<e_{1}, e_{2}, e_{3} \ldots . . e_{i}>$ according to the following principles;

2) Make $W_{i j}$ as small as possible under the condition of 1). Where $e_{i}$ is the edge, $e_{i}$ is the corresponding weight of edge $W_{i j}$; E is the set of edges.

When 2) cannot be carried out, the process stops.

The minimum spanning tree in graph theory can be obtained by using this algorithm. In this paper, the minimum spanning tree obtained by using the improved gravity model to calculate the weight of road is a city rail transit network which considers population, economy, passenger and freight traffic and other factors. 


\section{Model validation and Application}

This paper takes Handan city of Hebei Province as an example to verify the improved gravity model algorithm proposed above. Handan city has 6 districts, 1 Ge countylevel city and 11 counties, among which Hanshan District, Congtai district and Fuxing district are the central urban areas. Handan has unique location advantages. 309 National Highway, 107 national highway, 106 National Highway, Handan Dalian Expressway, Beijing Zhuhai Expressway and Qinglan Expressway intersect each other, creating a superior traffic location in Handan.

\subsection{Weight calculation of influencing factors and determination of gravity model}

First of all, the weight of the five indicators of permanent resident population, industrial added value, passenger volume, freight volume and urban per capita disposable income is determined by using the grey correlation analysis method. Based on the analysis of five basic data of Handan in 2014-2017, the data in the following table are from Handan national economic and social development statistical bulletin:

Table 1.2014-2017 years basic data table of Handan City.

\begin{tabular}{|l|l|l|l|l|l|}
\hline Particular year & $\begin{array}{l}\text { Permanent } \\
\text { population / } \\
10000\end{array}$ & $\begin{array}{l}\text { Industrial } \\
\text { added value / } \\
100 \text { million } \\
\text { yuan }\end{array}$ & $\begin{array}{l}\text { Passenger } \\
\text { capacity / } \\
10000 \text { people }\end{array}$ & $\begin{array}{l}\text { Freight volume } \\
\text { / 10000 tons }\end{array}$ & $\begin{array}{l}\text { Urban per } \\
\text { capita } \\
\text { disposable } \\
\text { income / yuan }\end{array}$ \\
\hline 2017 & 951.11 & 1783.7 & 5515.0 & 20867.1 & 28774 \\
\hline 2016 & 949.28 & 1387.3 & 5345.7 & 18744.3 & 26603 \\
\hline 2015 & 943.30 & 1323.6 & 5043.1 & 16963.2 & 24630 \\
\hline 2014 & 936.12 & 1205.1 & 4993.8 & 15421.1 & 22699 \\
\hline
\end{tabular}

Note: data in the table are from 2014-2017 national economic and social development statistical bulletin of Handan city.

Take $\mathrm{A}=(1,1,1,1)$ as the reference sequence, dimensionless the initial value of each factor sequence, calculate the difference $b$ etween the reference sequence and the analysis sequence, calculate the correlation coefficient between the analysis sequence and the reference sequence according to formula (2), and calculate the correlation value of each index according to formula (3). The data are listed in Table 2. According to the correlation value of each index in Table 2, the weight coefficient of each layer of index can be calculated. The specific results are as follows:

Table 2. Grey correlation coefficient and index weight table

\begin{tabular}{cccccc}
\hline Particular year & $\begin{array}{c}\text { Permanent } \\
\text { population }\end{array}$ & $\begin{array}{c}\text { Industrial } \\
\text { added value }\end{array}$ & $\begin{array}{c}\text { Passenger } \\
\text { traffic } \\
\text { volume }\end{array}$ & $\begin{array}{c}\text { The } \\
\text { volume } \\
\text { of freight } \\
\text { transport }\end{array}$ & $\begin{array}{c}\text { Urban per capita } \\
\text { disposable income }\end{array}$ \\
\hline 2017 & 1 & 1 & 1 & 1 & 1 \\
2016 & 0.988 & 0.422 & 0.841 & 0.615 & 0.683 \\
2015 & 0.952 & 0.386 & 0.921 & 0.842 & 0.874 \\
2014 & 0.911 & 0.333 & 0.913 & 0.791 & 0.824 \\
$\begin{array}{c}\text { Grey correlation } \\
\text { coefficient }\end{array}$ & 0.963 & 0.535 & 0.919 & 0.812 & 0.845 \\
Index weight & 0.236 & 0.131 & 0.225 & 0.199 & 0.207 \\
\hline
\end{tabular}

From the data in the table, it can be seen that the two indicators of permanent population and passenger volume have a larger weight, that is, they have a deeper impact on the determination of mutual attraction between cities and towns; the indicator of industrial added value has the



By using this formula, the weight of road in graph theory can be calculated. 


\subsection{Determination of urban rail transit network layout}

\subsubsection{Road network abstraction}

The following figure shows the current road network of Handan city. The yellow color block in the figure represents the central urban area of each county and city, and the central urban area of Handan city is in the ring. The pink line in the figure represents the expressway, the blue-green line represents the National Road, and the yellow line represents the provincial road.

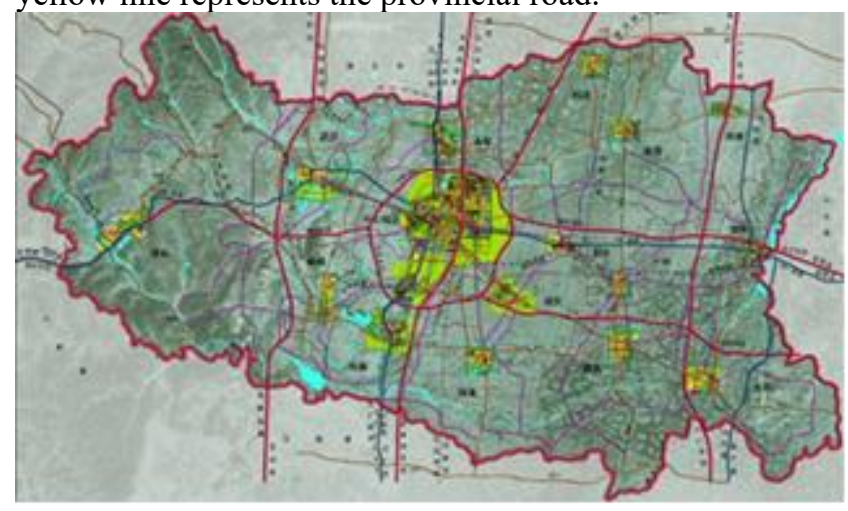

Figure1.Road network of Handan City

According to the current road network map of Handan City, look for roads at or above the county level that can connect each county and city in turn. If two counties and cities can be connected by roads at or above the county level, the two counties and cities will be connected by a virtual edge. If there is no such road between the two counties and cities, there will be no edge connection. For example, there are three routes to choose between Guang'an County and Qiu county, two of which are township roads, and the other is Quzhou County, so there is no direct connection between Guang'an County and Qiu county. The actual road network diagram is abstracted into the form of the figure below, with 15 vertices and 31 edges.

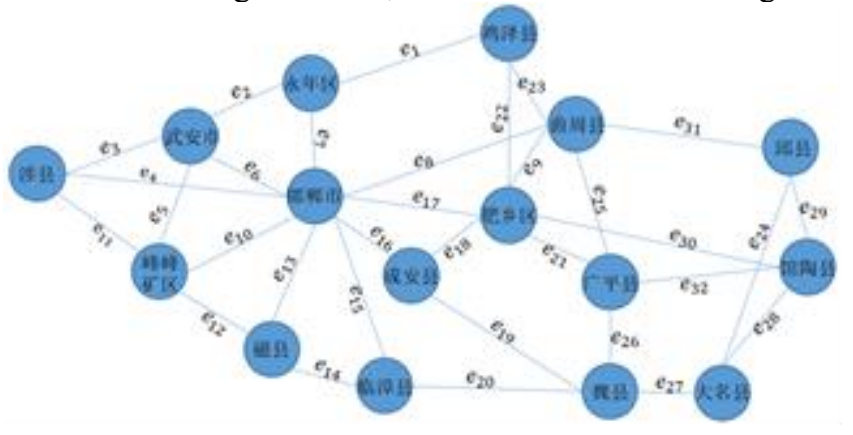

Figure2.Abstract diagram of road network in Handan

This is an undirected graph, in which $\boldsymbol{e}_{\mathbf{1}}-\boldsymbol{e}_{\mathbf{3 0}}$ is the number of the edge.

\subsubsection{Calculation of right of way}

Table 3. Data table of five indicators of counties and cities in Handan in 2017

\begin{tabular}{|c|c|c|c|c|c|}
\hline $\begin{array}{c}\text { Name of } \\
\text { county and } \\
\text { city }\end{array}$ & $\begin{array}{c}\text { Permanent } \\
\text { population / } \\
10000\end{array}$ & $\begin{array}{c}\text { Industrial added } \\
\text { value / } 100 \\
\text { million yuan }\end{array}$ & $\begin{array}{c}\text { Passenger } \\
\text { capacity / } \\
10000 \\
\text { people } \\
\end{array}$ & $\begin{array}{l}\text { Freight } \\
\text { volume / } \\
10000 \text { tons }\end{array}$ & $\begin{array}{c}\text { Urban per capita } \\
\text { disposable income / } \\
\text { yuan }\end{array}$ \\
\hline Handan City & 195.00 & 624.09 & 1095.92 & 7301.09 & 36984.84 \\
\hline Wuan City & 84.76 & 426.76 & 523.04 & 4992.57 & 34115.57 \\
\hline Jize County & 28.83 & 57.43 & 179.85 & 671.86 & 27860.73 \\
\hline Qiuxian & 23.51 & 42.86 & 147.98 & 501.41 & 31613.19 \\
\hline $\begin{array}{l}\text { Yongnian } \\
\text { District }\end{array}$ & 93.00 & 86.30 & 522.67 & 1009.60 & 31151.52 \\
\hline $\begin{array}{l}\text { Quzhou } \\
\text { County }\end{array}$ & 40.91 & 47.10 & 229.91 & 551.01 & 27163.77 \\
\hline $\begin{array}{c}\text { Feixiang } \\
\text { District }\end{array}$ & 33.49 & 30.33 & 203.08 & 354.82 & 26776.82 \\
\hline $\begin{array}{l}\text { Guantao } \\
\text { County }\end{array}$ & 31.72 & 40.60 & 195.74 & 474.97 & 23194.98 \\
\hline $\begin{array}{l}\text { Guang Ping } \\
\text { County }\end{array}$ & 27.67 & 30.16 & 167.48 & 352.83 & 22338.55 \\
\hline $\begin{array}{l}\text { Shexian } \\
\text { County }\end{array}$ & 42.42 & 45.44 & 264.62 & 531.59 & 21937.09 \\
\hline $\begin{array}{l}\text { Cheng An } \\
\text { county }\end{array}$ & 35.67 & 61.27 & 220.07 & 716.78 & 33161.01 \\
\hline Weixian & 78.81 & 53.36 & 442.84 & 624.25 & 31771.54 \\
\hline Cixian & 58.90 & 48.79 & 330.97 & 570.78 & 31342.21 \\
\hline $\begin{array}{l}\text { Daming } \\
\text { County }\end{array}$ & 62.27 & 47.21 & 349.90 & 552.29 & 27007.65 \\
\hline $\begin{array}{l}\text { Linzhang } \\
\text { County }\end{array}$ & 61.59 & 39.7 & 346.08 & 464.44 & 27755.91 \\
\hline
\end{tabular}




\begin{tabular}{cccccc}
$\begin{array}{c}\text { Fengfeng } \\
\text { mining area }\end{array}$ & 52.56 & 102.30 & 295.34 & 1196.78 & 25728.58 \\
total & 951.11 & 1783.70 & 5515.49 & 20867.07 & 459904.00 \\
\hline
\end{tabular}

Note: the data in the table are all from the statistical bulletin of national economic and social development of each county and city.

Find the distance between the two counties and cities connected by each side in turn, as shown in Table 4 below:

Table 4. Distance table between counties and cities

\begin{tabular}{|c|c|c|c|c|}
\hline $\begin{array}{c}\text { Serial } \\
\text { number }\end{array}$ & $\begin{array}{c}\text { Side } \\
\text { number }\end{array}$ & Name of county and city & $\begin{array}{c}\text { Name of county and } \\
\text { city }\end{array}$ & Distance / km \\
\hline 1 & $e_{1}$ & Yongnian District & Jize Country & 46.6 \\
\hline 2 & $e_{2}$ & Yongnian District & Wuan City & 38.6 \\
\hline 3 & $e_{3}$ & Wuan City & She Country & 49.2 \\
\hline 4 & $e_{4}$ & She Country & Handan City & 79.2 \\
\hline 5 & $e_{5}$ & Wuan City & Fengfeng mining area & 37.9 \\
\hline 6 & $e_{6}$ & Wuan City & Handan City & 28.6 \\
\hline 7 & $e_{7}$ & Yongnian District & Handan City & 18.9 \\
\hline 8 & $e_{8}$ & Handan City & Quzhou County & 47.8 \\
\hline 9 & $e_{9}$ & Quzhou County & Feixiang District & 38.9 \\
\hline 10 & $e_{10}$ & Handan City & Fengfeng mining area & 33.7 \\
\hline 11 & $e_{11}$ & She Country & Fengfeng mining area & 68.4 \\
\hline 12 & $e_{12}$ & Fengfeng mining area & Ci Country & 15.8 \\
\hline 13 & $e_{13}$ & Ci Country & Handan City & 31.2 \\
\hline 14 & $e_{14}$ & Ci Country & Linzhang County & 17.3 \\
\hline 15 & $e_{15}$ & Handan City & Linzhang County & 51.7 \\
\hline 16 & $e_{16}$ & Handan City & Cheng An county & 25.7 \\
\hline 17 & $e_{17}$ & Handan City & Feixiang District & 27.4 \\
\hline 18 & $e_{18}$ & Feixiang District & Cheng An county & 16.3 \\
\hline 19 & $e_{19}$ & Cheng An county & Wei Country & 22.9 \\
\hline 20 & $e_{20}$ & Linzhang Country & Wei Country & 30.9 \\
\hline 21 & $e_{21}$ & Feixiang District & Guangping Country & 15.5 \\
\hline 22 & $e_{22}$ & Jize Country & Feixiang District & 59.6 \\
\hline 23 & $e_{23}$ & Jize Country & Quzhou Country & 25.9 \\
\hline 24 & $e_{24}$ & Qiu Country & Daming Country & 65.6 \\
\hline 25 & $e_{25}$ & Quzhou Country & Guangping Country & 32.7 \\
\hline 26 & $e_{26}$ & Guang Ping Country & Wei Country & 14.6 \\
\hline 27 & $e_{27}$ & Wei Country & Daming Country & 19.6 \\
\hline 28 & $e_{28}$ & Guan Tao Country & Daming Country & 36.4 \\
\hline 29 & $e_{29}$ & Qiu Country & Guantao County & 37.7 \\
\hline 30 & $e_{30}$ & Feixiang District & Guantao County & 41.2 \\
\hline 31 & $e_{31}$ & Quzhou Country & Qiu Country & 17.2 \\
\hline 32 & $e_{32}$ & Guangping Country & Guantao County & 34.6 \\
\hline
\end{tabular}

The index weights in Table 2 and the data in Table 3 are substituted into formula (6), and the road weights on each side are calculated according to the abstract road network map in Figure 2, as shown in the following table:

Table 5. Table of road right value

\begin{tabular}{cc}
\hline ID & Right of way value \\
\hline$e_{1}$ & 435.07 \\
$e_{2}$ & 195.53 \\
$e_{3}$ & 309.85 \\
$e_{4}$ & 345.41 \\
$e_{5}$ & 222.32 \\
$e_{6}$ & 99.38 \\
$e_{7}$ & 71.43 \\
$e_{8}$ & 203.49 \\
$e_{9}$ & 594.43
\end{tabular}

$\begin{array}{ll}e_{10} & 139.36 \\ e_{11} & 723.82 \\ e_{12} & 151.34 \\ e_{13} & 125.73 \\ e_{14} & 207.31 \\ e_{15} & 212.02 \\ e_{16} & 106.41 \\ e_{17} & 118.89 \\ e_{18} & 231.80 \\ e_{19} & 239.42 \\ e_{20} & 343.58 \\ e_{21} & 190.26 \\ e_{22} & 913.23 \\ e_{23} & 353.16 \\ e_{24} & 872.17 \\ e_{25} & 522.22\end{array}$




\begin{tabular}{ll}
$e_{26}$ & 239.43 \\
$e_{27}$ & 208.76 \\
$e_{28}$ & 483.73 \\
$e_{29}$ & 621.94 \\
$e_{30}$ & 691.81 \\
$e_{31}$ & 257.33 \\
$e_{32}$ & 386.38 \\
\hline
\end{tabular}

Put the calculated right of way values in the table into the abstract road network map of Handan City, and the abstract road network map with weight can be obtained, as shown in the following figure:

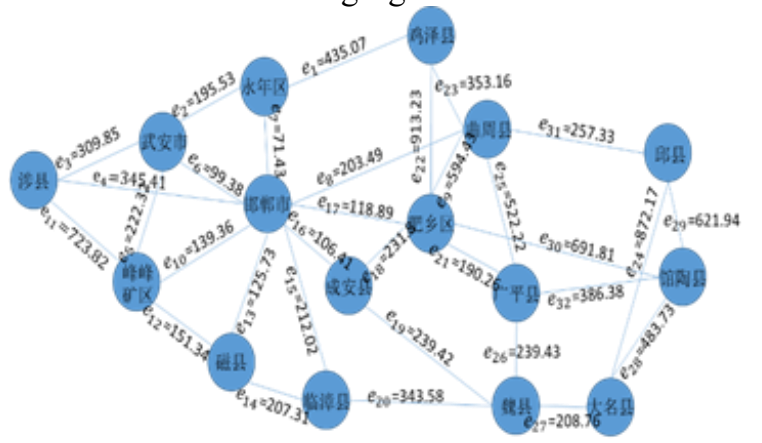

Figure3. Road Network Abstract diagram with right weight

Use Kruskal algorithm to solve the minimum spanning tree, i.e. urban rail transit network layout, as shown in the figure below:

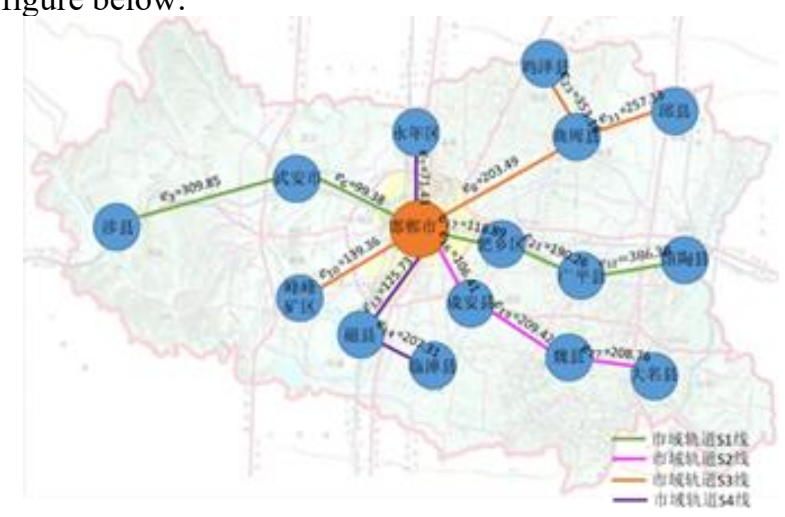

Figure4. The layout of prefecture city rail transit in Handan

The layout of urban rail transit network based on Kruskal algorithm is a reasonable route which can connect each county, city, district and take population, industry, economic level, passenger and freight traffic volume, distance and other factors into account. Handan, as a central prefecture level city, can be roughly divided into four lines with Handan as the center, one in the northsouth direction and three in the east-west direction, of which Handan is the central transfer station. The numbers of the four lines are S1, S2, S3 and S4, including She Country, Wu'an, Handan, Feixiang Country, Guangping Country and Guantao Country; Handan, Cheng'an, Wei Country and Daming Country; Fengfeng mining area, Handan, Quzhou Country and Qiuxian Country; Yongnian District, Handan and Cixian Linzhang county. This layout proves the importance of Handan as a prefecture level city to the whole region from the perspective of graph theory, and also proves the rationality of the mathematical model, which is more in line with the reality.

\section{5 conclusion}

The mutual attraction between cities and towns affects the layout of urban rail transit network. By analyzing the relevant factors that affect the attraction between cities and towns, this paper determines that five basic indicators are resident population, per capita disposable income (cities and towns), industrial added value, passenger and freight volume, and uses the gray correlation analysis method to determine the index weight. Considering five indexes and distances, an improved gravity model is constructed to describe the mutual attraction between two towns. The calculated value of the model is taken as the road weight, and the minimum spanning tree obtained by Kruskal algorithm is the urban rail transit network layout. The model is verified by the relevant data of Handan City, which has certain application value.

\section{Acknowledgments}

First of all, I would like to thank the leaders of the Research Institute of Highway Ministry of Transport for their support and encouragement in scientific research. Secondly, I would like to thank my colleagues for creating a good scientific research atmosphere for me. Finally, I would like to thank myself for their unremitting efforts.

\section{References}

1 Tu Yuting. Distribution of Intercity Rail Transit of Urban Agglomeration Based on the Node Important $[\mathrm{J}]$. Science and Technology Square, 2015 (2): 112-115.

2 Sun Youwang, Li Yunqing, Wang Xiang. Planning and Building of Urban Rail Traffic Network[J]. Journal of Shanghai Jiao Tong University, 2000 (S1): $52-55$.

3 Liu Xuan, Liu Yanfang, Zhang Mengke, et al. Research on Town Network Planning Based on Improved Gravity Model[J]. Geospatial Information, 2017, 15 (3): 8-11

4 Zhao Zhiming, Guan Hongzhi, Han Yan, et al. A Method for Determining Main Skeleton of Intercity Rail Transit Network Based on Bi-level Optimization Model [J]. Journal of Highway and Transportation Research and Development, 2015, 32 (10): 102-107.

$5 \mathrm{Hu}$ Liege, Cheng Liqin. Highway network layout of the city groups based on the layout method of node important degree with area location[J]. Journal of Railway Science and Engineering, 2008, 5(1):87-90..

6 Lv Tao, Yao Shimou, Cao Youhui, et al. Layout Patterns of the Intercity Rail Transit of Urban Agglomerations in China[J]. Progress in Geography, 2010, 29 (2): 249-256.

7 Li Xiaoli, Wang FAzeng, Luo Jun. Research of the Least Investment of Fast Railway main line for Zhong 
yuan Urban Cluster-Based on the Kruskal Algorithm of Graph Theory[J]. Areal Research and Development, 2008, 27 (5): 50-53.

8 CHURCH R L, CLIFFORD T J. Discussion of "Environmental Optimization of Power Lines"[J]. Journal of the Environmental Engineering Division, 1979,105(2) 438 - 439.

9 Fang Xinzhi. Research on Planning of Inter-city Rail Transit Network in Chengdu-Cohongqing Urban Agglomerations[D]. Southwest Jiaotong University,2009.

10 Zhou Fang. Research on Method of Urban Agglomeration Inter-city Rail Network Layout[D].Huazhong University of Science and Technology, 2011.

11 Zhu Fayong. Research on the Planning of City Agglomerations'inter-city Rail Network[D]. Southwest Jiaotong University, 2017.

12 Feng Jia, Xu Qi, Feng Xujie, et al. Influencing Factors of Energy Consumption for Rail Transport Based on the Grey Relational Degree[J]. Journal of Transportation Systems Engineering and Information Technology, 2011, 11 (1): 142-146.
13 Wang Wanqiu, Fang Shouen, Sun Daocheng, et al. Multi-Level Fuzzy Comprehensive Evaluation of Road Traffic Safety Management Facilities Based on Grey Relation Degree Analysis[J]. Journal of Wuhan University of Technology (Transportation Science \& Engineering), 2010, 34 (4): 652-656.

14 Long Yongun, Yang Qingyuan. Study the Spatial Influence of Urban Economic in Chong Qing[J]. Economic Geography, 2012, 32 (5): 71-76.

15 Wu Zhiqiang, Li Dehua. Principles of Urban Planning. Fourth Edition [M]. China Architecture \& Building Press, 2010.

$16 \mathrm{Wu}$ Jiansheng, Liu Hao, Peng Jian. Hierarchical Structure and Spatial Pattern of China's urban system - Evidence From DMSP/OLS Nightlight Data[J]. Acta Geographica Sinica, 2014, 69 (6): 759-770.

17 Carroll G R.. National City-size Distributions: What Do We Know After 67 Years of Research[J]. Progress in Human Geography,1982,6(1):1-43

18 Zhang Yi, Zhang Huanqi. Practice and Exploration of Graph Theory in Rural Passenger Transport Network[J]. Journal of Mathematics in Practice and Theory, 2006, 36 (2): 198-206. 